\title{
SOME BASIC RANDOM FIXED POINT THEOREMS WITH PPF DEPENDENCE AND FUNCTIONAL RANDOM DIFFERENTIAL EQUATIONS
}

\author{
Bapurao C. DHAGE
}

Abstract. In this paper two basic random fixed point theorems with PPF dependence are proved for random operators in separable Banach spaces with different domain and range spaces. The obtained abstract results are applied to certain nonlinear functional random differential equations for proving the existence results for random solutions with PPF dependence.

Mathematics subject classification (2010): 34K10, 47H10.

Keywords and phrases: Banach space, random contraction, random fixed point theorem, functional differential equation, random solution, PPF dependence.

\section{REFERENCES}

[1] S. R. BeRnField, V. LAKShMiKatham AND Y. M. REDDY, Fixed point theorems of operators with PPF dependence in Banach spaces, Applicable Anal., 6 (1977), 271-280.

[2] A. T. Bharucha-ReID, Fixed point theorems in probabilistic analysis, Bull. Amer. Math. Soc., 82 (1996), 611-645.

[3] B. C. DHAGE, Fixed point theorems with PPF dependence and functional differential equations, Fixed point Theory 12 (2011), (to appear).

[4] B. C. DHAGE, Quadratic perturbations of periodic boundary value problems of second order ordinary differential equations, Differ. Equ. Appl., 2 (2010), 465-486.

[5] Z. Drici, F. A. MCRAe And J. Vasundhara Devi, Fixed point theorems for mixed monotone operators with PPF dependence, Nonlinear Anal., 69 (2008), 632-636.

[6] Z. Drici, F. A. MCRAe And J. Vasundhara DeVi, Fixed-point theorems in partially ordered metric spaces for operators with PPF dependence, Nonlinear Anal., 67 (2007), 641-647.

[7] P. Hans, Random fixed point theorems, Transactions of the first Prague Conference on Information Theory, Statistical Decision Functions, Random Process, pp.105-125, (1957).

[8] C. J. Himmelberg, Measurable relations, Fund. Math., 87 (1975), 53-72.

[9] S. Iтон, Random fixed point theorems with applications to random differential equations in Banach spaces, J. Math. Anal. Appl., 67 (1979), 261-273.

[10] M. A. KRasnosels KII, Topological Methods in the Theory of Nonlinear Integral equations, Pergamon Press 1964.

[11] A. SPACEK, Zufallige Gleichungen, Czechoslaviak Math. J. 5 (1955), 462-466. 